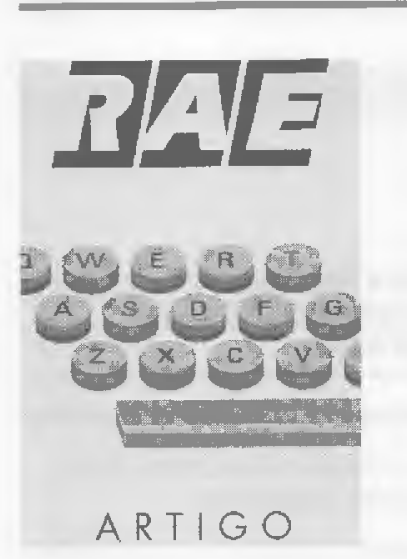

\title{
ESTRUTURA DE PRODUÇÃO E DESEMPENHO OPERACIONAL: IDENTIFICAÇÃO DE VARIÁVEIS-CHAVE ATRAVÉS DE SIMULAÇÃO
}

Como a técnica de simulação "Monte Carlo" poderia ser usada na análise de desempenho de mudanças em sistemas de produção.

How "Monte Carlo" simulation technique can be used in performance analysis of changes in production systems.

\section{INTRODUÇÃO}

A crescente globalização da atividade econômica, combinada com um acelerado ritmo de inovações tecnológicas, tem contribuído para o aumento da competição, tornando a competitividade um alvo móvel que necessita ser perseguido continuamente.

Neste processo, qualidade, inovatividade, prazos mais curtos e menores custos são as armas mais utilizadas pelas empresas que se destacaram como
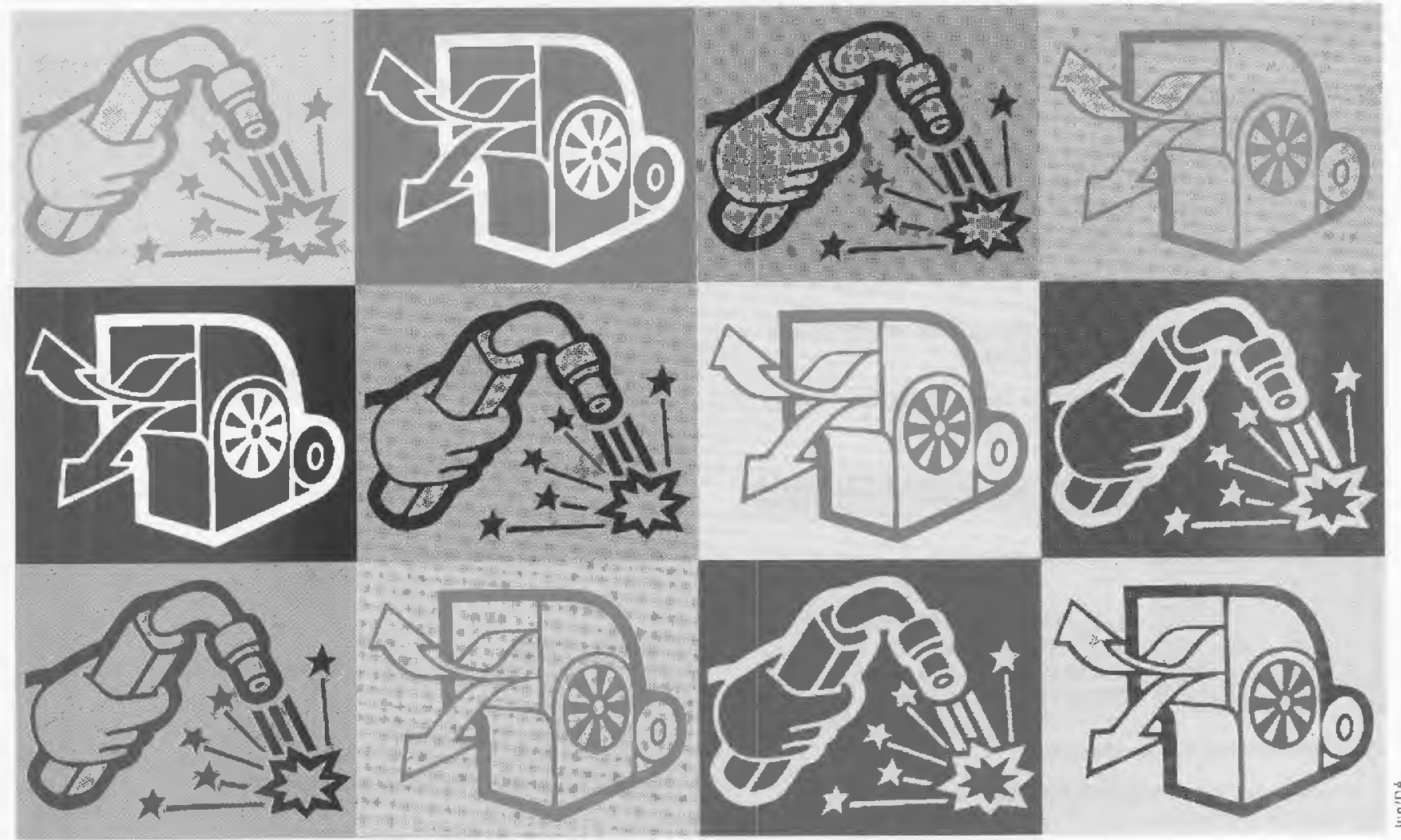

* Professor do COPPEADIUFRJ e Titular da Cátedra lpiranga de Estratégia de Operaçöes. 
competidoras de classe mundial. Isto implica um aumento das responsabilidades e desafios para as pessoas que gerenciam as atividades de manufatura nas organizações.

Uma conseqüência observada desta nova postura competitiva é a redução do ciclo de vida dos produtos e dos sistemas produtivos, fazendo com que a capacidade de se projetar e implementar sistemas de produção eficazes e eficientes se torne cada vez mais um fator crucial para a competitividade empresarial.

Projetar e implementar sistemas de produção implica, na maioria das vezes, a introdução de tecnologias de processo, afetando diretamente a estrutura hardwuare de operações e os sistemas de controle software, assim como o sistema social da organização peopleware, conforme ressaltado por Chase e Aquilano. ${ }^{1}$ Estes efeitos não devem ser desprezados, pois têm impacto direto sobre a competitividade através de:

- menores custos e/ou;

- maior qualidade;

- entregas confiáveis;

- entregas mais rápidas;

- capacidade de lançar novos produtos;

- capacidade de responder eficazmente a variações de volume.

Estes parâmetros são, em grande parte, dependentes da estrutura de operaçóes e dos sistemas de controle, que, por sua vez, deveriam ser projetados para se ajustarem à tecnologia de processo utilizada. ${ }^{2}$

No caso da introdução de uma nova tecnologia de processo, torna-se extremamente útil simular o novo sistema de produção e os procedimentos de controle, antes da implementação. Isto pode ser conseguido através da construção de um modelo em computador, que permita a execução de um amplo conjunto de testes sobre os parâmetros e regras de operação do sistema.

Este trabalho procura demonstrar com um exemplo real este tipo de abordagem. Para tanto, foi utilizado um modelo de simulaçäo de um novo sistema de produção, em implantação por uma empresa do setor de componentes de calçados.
A empresa havia sido criada recentemente, como subsidiária de um grande grupo industrial fabricante de calçados. $\mathrm{Na}$ busca do aumento da produtividade, o grupo buscava o aperfeiçoamento tecnológico permanente de seus produtos, através da utilização de novos materiais e novos processos de fabricação.

A subsidiária fora criada com o objetivo de fornecer palmilhas de plástico para calçados femininos, em substituição ao processo tradicional que utiliza-

\section{Apesar do novo sistema de}

produção representar uma

grande simplificação do fluxo de

materiais e das operações, ele

se caracterizava pela exigência

de volumes de investimentos

significativamente superiores

aos exigidos pela tecnologia

tradicional.

va cartolina, metal e couro, envolvendo um conjunto complexo de operaçốes. A nova tecnologia, que utilizava o processo de injeção de plástico em moldes metálicos, tinha a vantagem de oferecer melhor qualidade a um menor custo, pela simplificação do número de operações, que se reduziria praticamente a uma única.

Apesar do novo sistema de produção representar uma grande simplificação do fluxo de materiais e das operaçôes, ele se caracterizava pela exigência de volumes de investimentos significativamente superiores aos exigidos pela tecnologia tradicional. Além disso, por ser um processo inovador, não existiam conhecimentos disponíveis sobre a melhor forma de operação, no que diz respeito ao dimensionamento, programação e controle da produção.

O objetivo deste trabalho é, portanto, analisar a sensibilidade do novo sistema, no que diz respeito a seu desempenho operacional, a variações em algu-
1. CHASE, R., ACHILANO, N. Production and operations management; a life cycle approach. Homewood, III.: R.D. Irwin, 1977

2. FLEURY, P. F. S.S., PROENÇA, A. Competitividade industrial e a geréncia estratégica de operações. Rio de Janeiro: COPPEAD/UFRJ, julho de 1991 (Relatório COPPEAD, 253). 
mas de suas principais variáveis estruturais e de controle.

O sistema de produção analisado tem características bastante especiais. As principais características do sistema de produção são:

- o produto, palmilhas de plástico injetado, que precisa ser produzido em diferentes formatos e tamanhos. Cada formato particular é denominado estilo e se compõe de um conjunto de até treze tamanhos diferentes;

- o equipamento, máquinas injetoras com múltiplas estações de trabalho, onde cada máquina possui doze estações, organizadas em uma mesa circular que se move em torno do seu eixo, necessita de um único operador. As estações são capazes de receber qualquer molde, significando que uma máquina pode fabricar, simultaneamente, palmilhas de diferentes estilos e tamanhos. A montagem de um molde numa estação qualquer, consome uma quantidade substancial de tempo;

- o padrão da demanda, ou das encomendas para fabricação, caracterizado pelo fato de que quando um cliente faz uma encomenda de um produto de determinado estilo, ele usualmente pede a gama completa de tamanhos, em quantidades variadas em função do tamanho. Devido à política de só dar início à produção após o recebimento de uma encomenda firme, cada encomenda representa a produção e a entrega conjunta de até treze diferentes lotes de componentes.

\section{O PROJETO DE EXPERIMENTOS}

O estudo foi executado em duas fases complementares. A primeira (na qual foram utilizados dados reais da empresa mencionada anteriormente), tinha o caráter exploratório. Os objetivos principais desta fase eram validar o modelo e identificar as principais características do sistema, com o objetivo de determinar valores típicos para as variáveis, $\mathrm{e}$ desenvolver regras de controle que fossem apropriadas às características do sistema em estudo.
A segunda fase consistiu de um conjunto planejado de experimentos, com o objetivo de gerar informações que pudessem levar a um conjunto mais geral de conclusões a respeito desta classe de sistema de produção. Os parâmetros utilizados nesta segunda fase, e listados abaixo, foram determinados a partir da fase inicial de experimentos.

As duas fases do estudo complementaram uma a outra, no sentido de que a escolha das variáveis e seus valores, assim como o projeto de experimentos da segunda fase, foram fortemente baseadas nas informações obtidas na primeira fase.

O principal objetivo do estudo era obter informações conclusivas sobre a sensibilidade do sistema a variações em seis de suas variáveis, que pareciam influenciar mais fortemente seu desempenho. Estas variáveis representam respectivamente o padrão de encomendas do mercado (variável 1), a política de capacidade de produção (variáveis 2 e $3)$, procedimentos de programação e controle da produção (variáveis 4 e 5) e efeitos de economia de escala e organização da produção (variável 6), segundo especificado abaixo:

1. o tamanho médio das encomendas: um valor menor (1000 itens), contra um valor maior (1600 itens);

2. o número de moldes disponiveis para produção: um número baixo (27 moldes), contra um número alto (42 moldes);

3. o indice médio de utilização da capacidade de produção: um índice baixo $(65 \%)$, contra um índice alto (85\%);

4. a regra de partição das encomendas em lotes menores de fabricação: as opções eram de particionar lotes superiores a 450 itens, ou nunca particionar os lotes para fabricação;

5. o tempo médio de troca de ferramentas: um valor baixo (8 min.), contra um valor alto (16 min.);

6. a proporção entre o número de estilos (linhas de produto), e o número de máquinas injetoras: uma proporção menor 


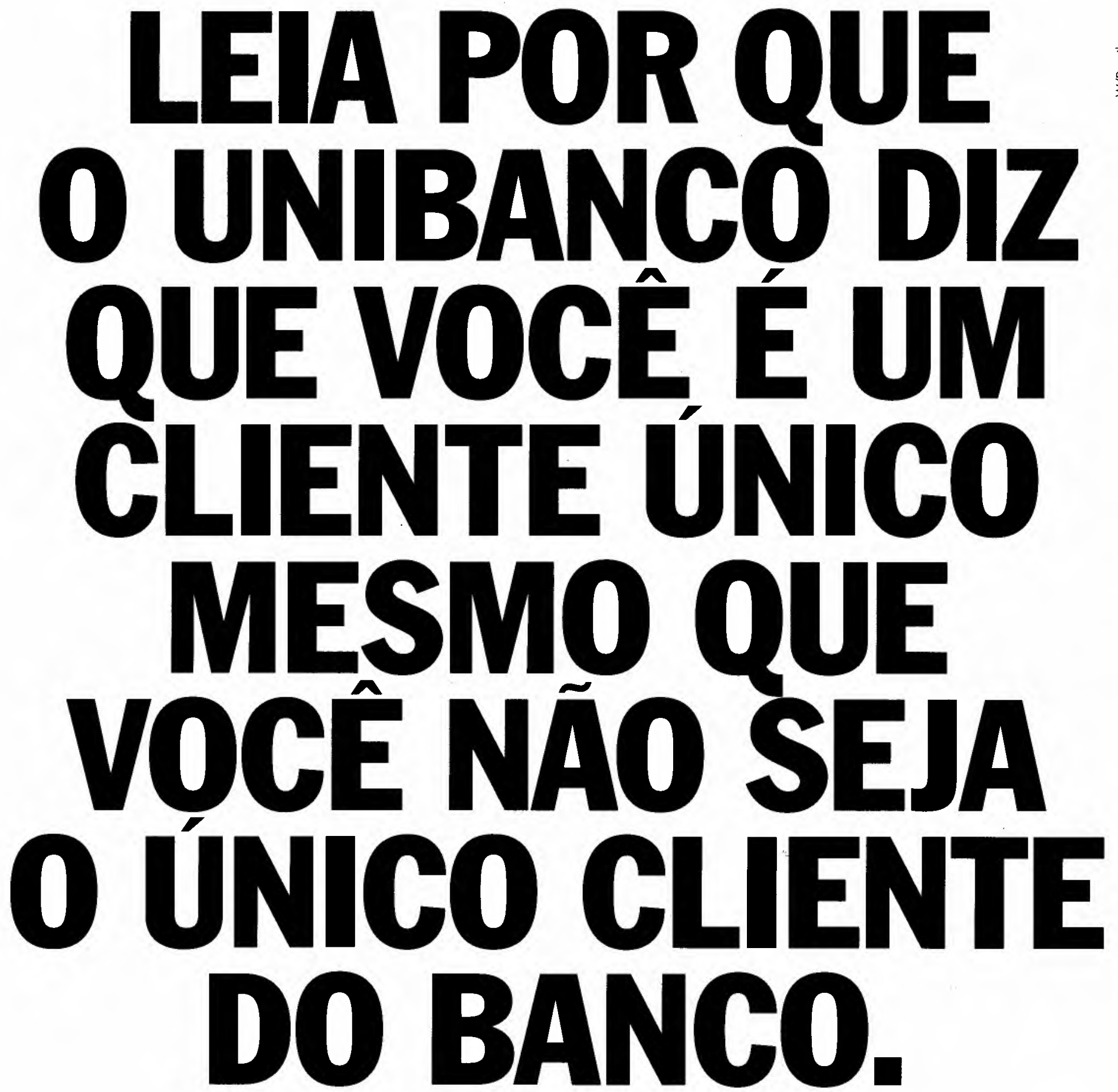

O banco único tem vários bancos únicos dentro de si. Existe um banco único para grupos empresariais e, ao mesmo tempo, um banco único para serviços de pessoas físicas. Existe um banco único para negócios de alta renda e, ao mesmo tempo, um banco único para investimentos cotidianos dos seus correntistas. $E$ assim, com estruturas especializadas em resolver necessidades específicas de diferentes clientes, o banco único oferece investimentos únicos para você que, não por acaso, é chamado de cliente exclusivo.
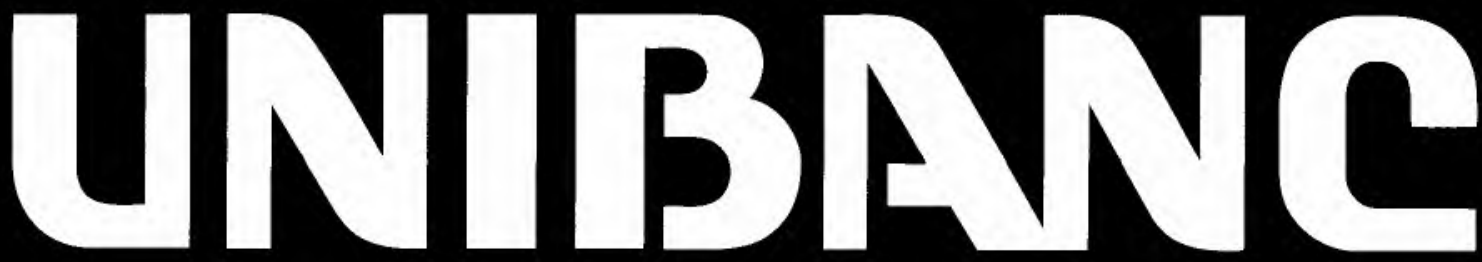
3. DAVIES, O.L. The design and analyses of industrial experiments. London: Oliver and Boyd, 1967
(3/2), contra uma proporção maior (3/1). Considerando que o número de estilos pode ser mantido constante (3), é possível expressar a variável pelo número de máquinas ( 2 contra 1 ).

Uma vez selecionadas as variáveis a serem analisadas e seus possíveis valores, tornava-se necessário desenvolver um projeto de experimentos. Considerando o objetivo do estudo, seria uma tarefa relativamente simples executar uma série de alteraçöes independentes nos valores, uma de cada vez, e medir os efeitos destas modificações. Este procedimento, no entanto, apresenta duas limitações:

1. o efeito de interações entre variáveis seria ignorado. É bem possível que uma mudança no valor de uma variável impacte o desempenho do sistema apenas nos casos onde outra variável também tenha sido modificada. Por exemplo, o aumento no número de moldes, de 27 para 45, poderia ter impacto sobre o desempenho do sistema, apenas nos casos onde a relação número de estilos/número de máquinas fosse de $3 / 2$. Tais interações podem ser importantes e não deveriam ser ignoradas;

2. seria difícil generalizar os resultados. Se apenas mudanças isoladas fossem realizadas, o efeito destas mudanças poderia ser considerado válido apenas para situaçōes muito próximas da configuração do sistema utilizado naquele experimento específico. $\mathrm{O}$ ideal é que cada mudança individual fosse analisada em relação a uma ampla variedade de configurações do sistema.
Para contornar estes problemas, decidiu-se por utilizar um projeto fatorial de experimentos, onde as seis variáveis fossem consideradas os fatores, e seus valores, os niveis dos fatores. ${ }^{3}$ Se um projeto fatorial completo fosse utilizado, seriam necessários um total de 64 (26) experimentos, o que representaria uma esforço computacional considerável.

Para minimizar esta dificuldade, existe a possibilidade de utilizar um projeto fatorial fracionado, que permitiria uma

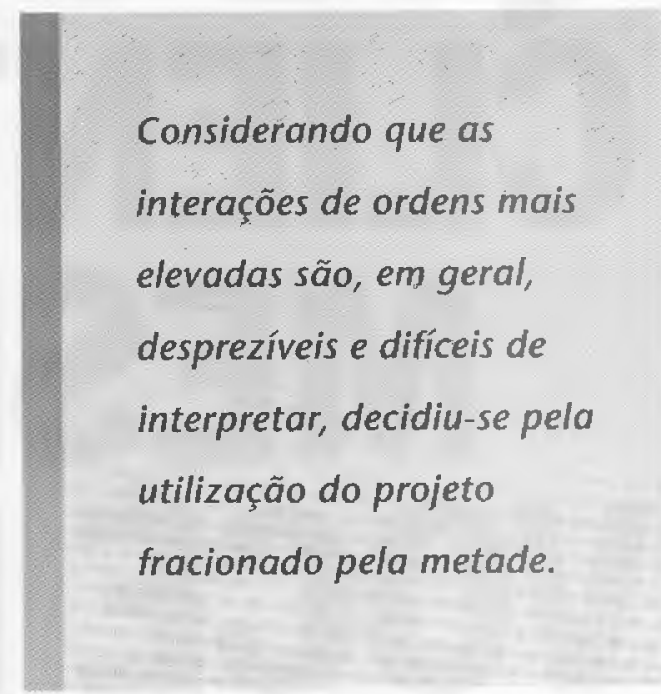

redução considerável no númeru de experimentos, com grande economia de esforço computacional. Tal projeto permite a estimação dos efeitos principais e das interações de mais baixa ordem.

Se um projeto fatorial fracionado pela metade fosse utilizado, seriam necessários apenas 32 experimentos, e ainda seria possível medir todos os efeitos principais e as interações de primeira ordem. Considerando que as interações de ordens mais elevadas são, em geral, 


\section{ANEXO 1 - COMENTÁRIOS METODOLÓGICOS}

A. 0 procedimento estatístico utilizado no estuda teve as seguintes características.

1. Com relação às questões táticas do projeto de experimentos:

1.1. Cada experimento foi incializado na condição de "fila vazia", ou seja, máquinas descarregadas, e nenhum pedido na fila;

1.2. Existe um periodo de "estabilização" do sistema, equivalente a 20 ordens completadas (duzentos e cinquenta "lotes" de componentes);

1.3. As estatísticas para análise do sistema só começam a ser computadas após este período;

1.4. 0 tamanho do período de estabilização foi determinado a partir de análise estatística de resultados de um pré-teste do modelo;

1.5. Para cada experimento foram rodados doze pares antitéticos de corridas, onde cada corrida correspondia a 150 pedidos completados, ou seja, cerca de 1.700 "lotes" de componentes.

2. Com relação aos testes estatisticos:

Para testar a significância estatistica dos efeitos principais e secundários, foram utilizados testes " $F$ " đe análise de variância das médias encontradas nos doze pares de corridas. O teste "F" se baseia na hipótese nula de que as mudanças nas variáveis do sistema nāo causam nenhum efeito estatisticamente significativo do desempertho do sistema.

B. O procedimento para a quebra de pedidos se baseia nos seguintes princípios:

1. Como já descrito anteriormente no corpo do trabalho, cada pedido é composto por vários (até treze) "lotes" de componentes. Cada lote corresponde a um tamanho especifico de calçado e exige um molde específico.

2. A fila de espera é formada pelo conjunto de "lotes" de componentes. Cada pedido pode implicar na entrada de até treze "lotes" na fila.

3. Como existe a possibilidade de se ter mais de 1 molde do mesmo tamanho e estilo, a alternativa de se quebrar um lote em 2 ou mais sublotes, poderia permitir a produção simultânea do mesmo lote, utilizanda-se dos moldes duplicados.

4. Em caso de partição, qualquer lote de componentes com mais de 450 itens era dividido em dois ou mais sublotes, de tal maneira que nenhum sublote permanecesse com mais de 450 itens.

C. A fixação dos prazos de entrega era função de política estabelecida pela empresa, de garantir entregas num prazo máximo de oito dias úteis a partir da data do pedido, qualquer que fosse o pedido. Em nenhuma situação os pedidos eram entregues parceladamente, mesmo quando se adotava o procedimento de quebra dos pedidos em lotes menores de componéntes.

D. Durante os experimentos realizados, a prioridade útilizada para o seqüenciamento da fila, foi uma derivação da regra FIFO (primeiro que chega é o primeiro que entra), denominada FIFOMB, que a partir da fila formada pela regra FIFO, dá uma prioridade adicional àqueles lotes de componentes para os quais já houvesse um molde vazio já montado na máquina.

despreziveis e difíceis de interpretar, decidiu-se pela utilização do projeto fracionado pela metade.

Com o objetivo de tornar as referências futuras mais simplificadas, as variáveis e seus valores serão tabulados e associados a letras e nomes abreviados, como apresentado na tabela 1.

Com base na notação acima, uma configuração do sistema onde $\mathrm{A}=85, \mathrm{~B}$ $=16, \mathrm{C}=27, \mathrm{D}=1600, \mathrm{E}=\mathrm{Não}, \mathrm{F}=1$, seria denominada como abcdef (todas as variáveis estariam com seu valor alternativo 1). Por outro lado, se $\mathrm{A}=65, \mathrm{~B}=$ $8, C=42, D=1000, E=450$ e $F=2$, a configuração do sistema seria denominada (I) (todas as variáveis estāo com seu valor padrão 0 ).
É interessante observar que os valores das variáveis foram divididos de tal maneira que (I) e abcdef representam respectivamente os sistemas mais "folgados" (baixa utilização de capacidade, pequeno tempo de set up, número maior de moldes, pedidos de tamanho pequeno, uso da partição de lotes e uma relação mais favorável entre número de modelos e número de máquinas) e mais "apertados" (maior utilização da capacidade, maior tempo de set up; pequeno número de moldes, encomendas grandes, lotes não sofrem partição, relação mais desfavorável entre número de estilos e número de máquinas).

A descrição mais detalhada do projeto de experimentos utilizado pode ser encontrada no trabalho de Fleury. ${ }^{4}$
4.FLEURY, P.F.S.S. Operation strategies for a shoe batch manufaturing system. Loughborough: University of Technology, 1976. (Tese de Doutorado) 
Para medir o desempenho do sistema de produção, foram utilizadas variáveis relacionadas aos prazos de entrega, assim como medidas de performance internas, tais como número de pedidos esperando na "fila" para serem processados e nível de ociosidade devido à troca de ferramentas. No que diz respeito a medidas de desempenho relacionadas aos prazos de entrega, foram utilizados o prazo de entrega throughput time de uma encomenda, assim como o percentual da produção entregue fora do prazo.

\section{APRESENTAÇÃO DOS RESULTADOS}

Os resultados obtidos pelo modelo de simulação foram submetidos a testes de significância estatística, com o objetivo de permitir sua generalização, para o tipo de sistema de produção estudado. Desta forma, serão considerados apenas aqueles resultados que tenham apresentado significância estatística.

Para melhor interpretá-los, torna-se conveniente comparar inicialmente o desempenho do sistema para as duas configurações extremas, (I) e abcdef, com a média de desempenho de todas as configurações.

Os dados da tabela 2 indicam que existem grandes diferenças de performance entre a configuração mais folgada (I) e a mais apertada ( $a b c d e f$ ), principalmente no que diz respeito aos prazos de entrega.

O percentual da produção entregue com atraso, que na configuração (I) é de apenas $1,93 \%$ (nível de serviço de $98,07 \%$ ), na configuração abcdef, aumenta mais de vinte vezes atingindo o valor de $40,65 \%$. Da mesma forma, o prazo médio de entrega, que na configuração (I) é de 2,99 dias, passa para 8,38 dias.

Em termos do comportamento interno do sistema, o número de pedidos es- perando na fila aumenta substancialmente (de 16,56 para 35,28 ) quando se passa de (I) para abcdef, mas a ocosidade devido ao set up é pouco afetada $(6,22 \%$ para $7,21 \%$ ).

A partir da constatação de que existem grandes espaços para melhorar a performance a partir da manipulação de variáveis do sistema, surge imediatamente a pergunta; das 6 variáveis manipuladas, quais aquelas que mais afetam o desempenho do sistema? Existem in-

\section{O projeto fatorial permite}

responder a estas questóes

de forma inequívoca, ao

isolar os efeitos principal e

secundário das variáveis.

terações significativas entre pares de variáveis? O projeto fatorial permite responder a estas questões de forma inequívoca, ao isolar os efeitos principal e secundário das variáveis.

O efeito principal indica a importância de uma dada variável para esta classe de sistema, considerando-se o conjunto de todas as configurações. O efeito secundário indica possíveis ințerações entre pares de variáveis. A tabela 3 apresenta os resultados estatisticamente significativos dos efeitos principais e secundários.

\begin{tabular}{|cccc|}
\hline & Tabela 2 & & \\
& $(1)$ & abcofef & média \\
\hline & & 8,38 & 5,72 \\
Tempo médio entrega (dias) & 2,99 & 40,65 & 20,35 \\
\% entregue c/atraso (\%) & 1,93 & 35,28 & 34,11 \\
Pedidos na fila & 16,56 & 7,21 & 6,61 \\
Ociosidade de set up (\%) & 6,22 & & \\
\hline
\end{tabular}




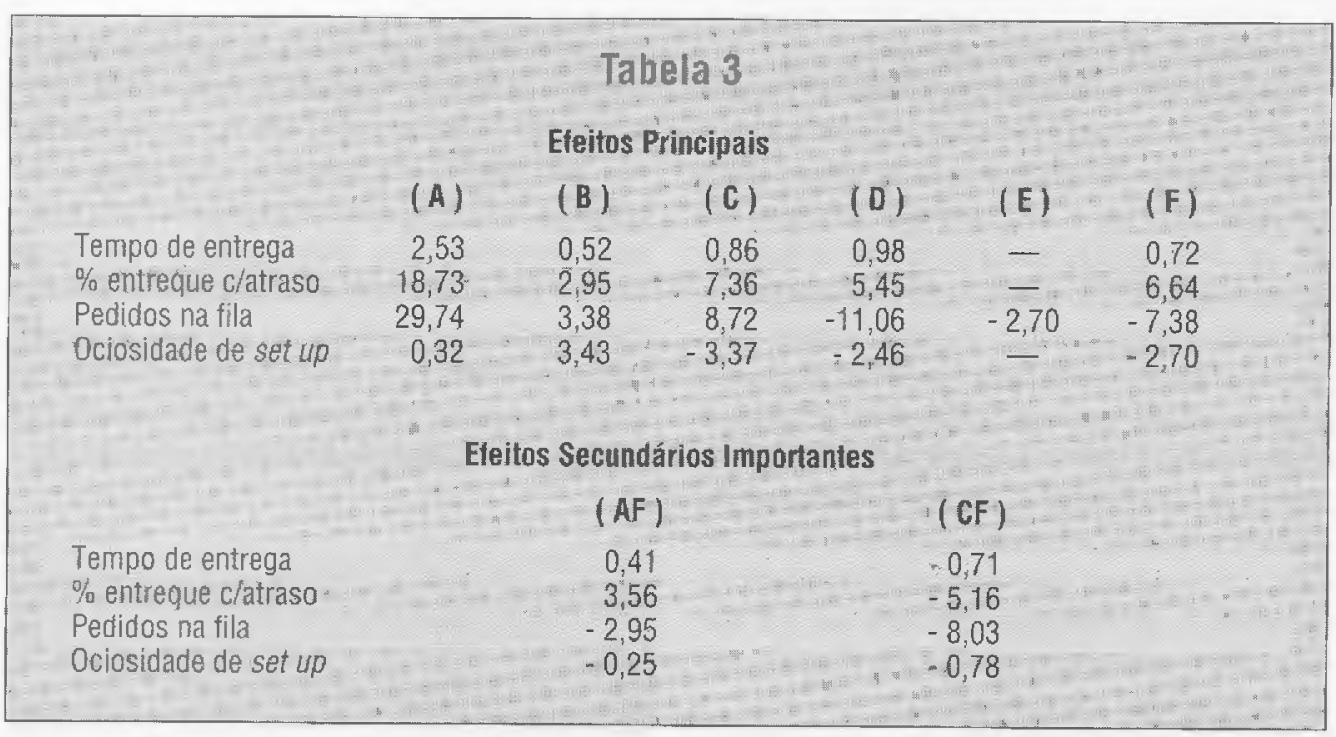

A análise da tabela 3 acima permite identificar a importância relativa das diversas variáveis sobre a performance do sistema.

\section{Variável $A$ (Nível de utilização da capacidade)}

De longe, a variável que tem maior influência sobre o desempenho do sistema é $A$, que corresponde ao nível de utilização da capacidade instalada, conseqüência da relação entre demanda e oferta de horas de máquina. Uma redução no nível de utilização da capacidade, de $85 \%$ para $65 \%$, resulta numa significativa melhoria em todas as medidas de performance, com exceção da ociosidade causada pelo set up.

Para aquilatar a dimensăo desta influência, basta observar que o efeito principal desta mudança é reduzir o tempo médio de entrega em 2,53 dias, a produção entregue com atraso em $18,73 \%$, o número de pedidos na fila em 29,74 e a ociosidade devido ao set up em $0,32 \%$, em termos absolutos. Em outras palavras, isto significa que:

- quando o nível de utilização da capacidade é de $85 \%$, o tempo médio de entrega é de 6,98 dias, $29,71 \%$ da produção é entregue com atraso, o número de pedidos na fila é 49,98 e a ociosidade devido ao set up é de $6,77 \%$;

- quando o nível de utilização é reduzido para $65 \%$, o tempo médio de entre- ga cai para 4,45 dias, a produção entregue com atraso se reduz para $10,98 \%$, o número de pedidos na fila diminui para 19,24 e a ociosidade devido ao set up baixa para $6,45 \%$.

Ou seja, uma redução de cerca de $23,5 \%$ no nível de utilização da capacidade resulta numa diminuição de cerca de:

- $63 \%$ no percentual de entregas fora do prazo;

- $36 \%$ no prazo médio de entrega;

- $62 \%$ no número de pedidos na fila;

- $5 \%$ na ociosidade devido ao set up.

Embora haja uma interação estatisticamente significativa entre o nível de utilização da capacidade instalada (variável $A$ ) e a relação número de estilos/número de máquinas (variável $F$ ), a magnitude desta interaçāo é suficientemente pequena comparada com o efeito principal (cerca de 16\%). Por esta razão é possível afirmar que o nível de utilização da capacidade instalada influencia fortemente este tipo de sistema de produção, dentro de uma ampla gama de configurações. Para comprovar esta afirmação, basta observar que o efeito principal sobre o percentual da produção entregue fora do prazo, que em média é de $18,73 \%$, passa a ser $22,29 \%$ para os casos onde o número de máquinas é 1 e $15,97 \%$ quando o número de máquinas é 2 . 
Variável $B$ (Tempo de set up)

Depois da partição dos lotes, o tempo de set up é a variável que menos afeta o desempenho do sistema, com uma única exceção óbvia, a ociosidade devido ao set up. Seu efeito médio sobre o tempo de entrega (0,52 dias), embora estatisticamente significativo, é cinco vezes menor que o causado pela variável $A$. Sobre o percentual entregue fora do prazo, o efeito é de $2,95 \%$, ou seja 6,5 vezes menor que a variável $A$. Sobre o número de pedidos na fila, o efeito é igual a 3,38 , ou seja, nove vezes menor que a variável $A$. Quanto à ociosidade devido ao set up, seu efeito principal de $3,43 \%$ é onze vezes maior que a variável $A$.

Um outro indicador de que a única influência importante da variável $B$ é sobre a ociosidade devido ao set up é o fato de que para um aumento de $100 \%$ no seu valor (de 8 para 16 minutos), as conseqüências foram:

- aumento de $10 \%$ no tempo médio de entrega;

- aumento de $16 \%$ no percentual entregue fora do prazo;

- aumento de $11 \%$ no número de pedidos na fila;

- aumento de $70 \%$ na ociosidade devido ao set up.

Como não foi constatada nenhuma interação significativa entre a variável $B$ $e$ as outras cinco variáveis, pode-se afirmar que estas características do tempo do set up são verdadeiras para qualquer configuração do sistema, obviamente dentro dos limites testados.

\section{Variável C (Número de moldes)}

Embora o efeito principal do número de moldes sobre o desempenho do siste- ma apresente um valor estatisticamente significativo, (o segundo fator mais importante após a variável $A$, e responsável por $15,3 \%$ da variação no tempo de entrega, $17,9 \%$ da variação no percentual da produção entregue fora do prazo, $13,8 \%$ dos pedidos em fila e $27,4 \%$ da ociosidade devido ao set up), o efeito isolado tem pouco significado em si mesmo, pois os resultados mostram uma grande interação com a variável $F$.

\section{Em outras palavras, \\ o aumento do número \\ de moldes só afeta \\ significativamente 0 \\ desempenho do sistema nos \\ casos onde se aumenta \\ também a relação número \\ de máquinas/número \\ de moldes.}

Para comprovar isto basta examinar a tabela 4 .

Tais números significam que só faz sentido analisar o efeito do número de moldes levando-se em consideração também o número de máquinas. Assim, o efeito principal sobre o percentual entregue fora do prazo é de $12,52 \%$, nos casos onde o número de máquinas é 2 , e apenas $2,2 \%$ quando o número de máquinas é 1 .

Em outras palavras, o aumento do número de moldes só afeta significati-

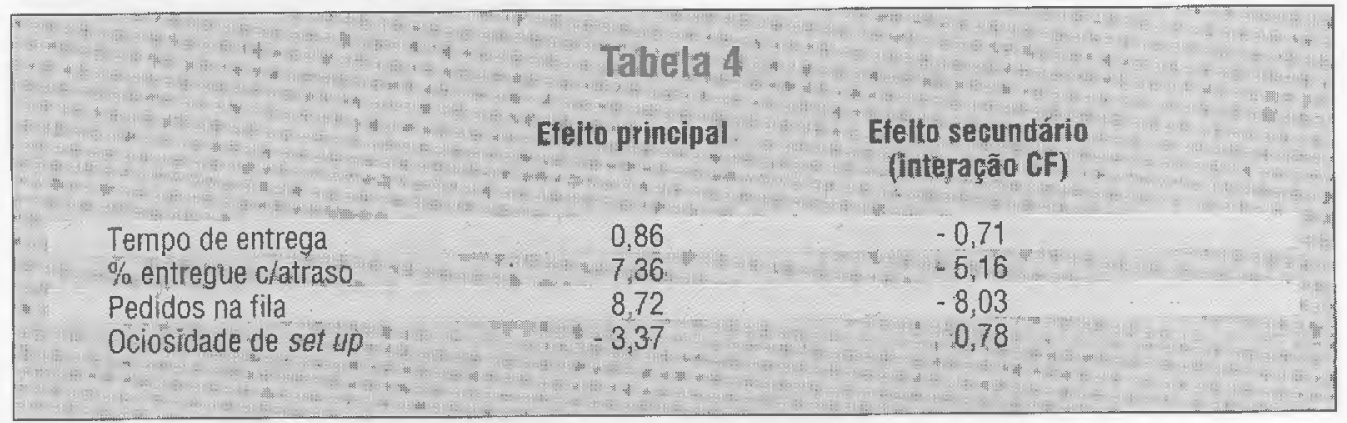


vamente o desempenho do sistema nos casos onde se aumenta também a relação número de máquinas/número de moldes. Assim, nas situações onde o número de máquinas é igual a 2 , o aumento no número de moldes de 27 para 42 (um aumento de 59\%) resulta numa redução do percentual entregue com atraso de $26,51 \%$ para $14,09 \%$. Nos casos onde o número de máquinas é 1 , o mesmo aumento no número de moldes resulta numa redução do percentual entregue com atraso de $21,95 \%$ para $19,25 \%$.

\section{Variável $D$ (Tamanho dos pedidos)}

O tamanho médio dos pedidos tem um efeito estatisticamente significativo sobre o desempenho do sistema, mas numa escala bem inferior à variável $A \mathrm{e}$ com resultados conflitantes. Assim, uma redução de $37 \%$ no tamanho médio dos pedidos (de 1600 itens por pedido, para 1000 itens por pedido, mantendose o mesmo volume total pedido por mês), resulta em:

- redução de $15 \%$ no tempo médio de entrega;

- redução de $23 \%$ no percentual entregue com atraso;

- aumento de $45 \%$ na ociosidade devido ao set up;

- aumento de $40 \%$ no número de pedidos na fila.

Verifica-se, portanto, que se por um lado a redução no tamanho médio dos pedidos permite uma melhoria razoável no desempenho externo do sistema (prazos de entrega), por outro, ele afeta negativamente o desempenho interno do sistema, aumentando o tamanho das filas e piorando os índices de ociosidade.

\section{Variável $E$ (Partição dos lotes para fabricação)}

A tática de particionar os pedidos em lotes menores de fabricação, buscando desta forma uma maior flexibilidade na utilização das máquinas e moldes, não afeta o desempenho do sistema, a não ser em uma única dimensão, ou seja, no número médio de pedidos na fila e, assim mesmo, moderadamente.

\section{Variável $F$ (Número de Máquinas)}

Embora o efeito principal do número de máquinas sobre o desempenho do sistema apresente um valor estatisticamente significativo (o terceiro fator mais importante após as variáveis $A \mathrm{e}$ C), o efeito isolado tem pouco significado em si mesmo, pois os resultados mostram uma grande interação com as variáveis $C$ e $A$.

Para comprovar isto basta examinar a tabela 5 .

Tais números significam que só faz sentido analisar o efeito do número de máquinas levando-se em consideração também o número de moldes e/ou o nível de utilização de capacidade. Desta forma, o efeito principal sobre o percentual entregue fora do prazo é de $11,80 \%$ nos casos onde o número de moldes é 42 , e apenas $1,48 \%$ quando o número de moldes é 27. Da mesma forma, quando o nível de utilização de capacidade é $85 \%$, o efeito principal do número de máquinas é significativamente maior do que quando o nível de utilização é de $65 \%$, ou seja, $10,20 \%$ contra $3,08 \%$.

Em outras palavras, o aumento do número de máquinas só afeta positivamente o desempenho do sistema nos casos onde se aumenta também o número de moldes ou quando o nível de utilização da capacidade é alto. Assim, nas si-

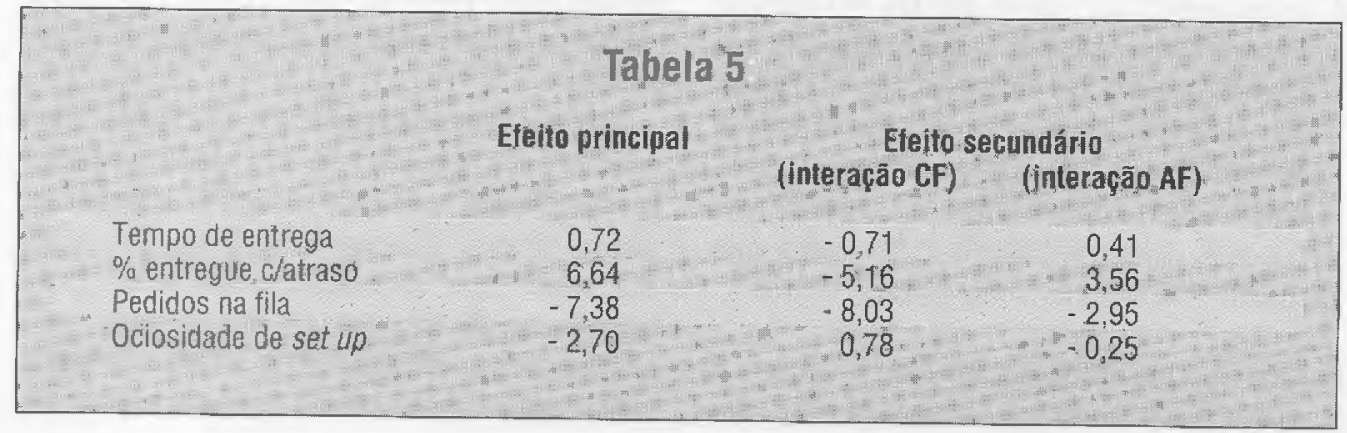


5. GANTELLOW, D.G. et al Machine shop problems: an operational research approach. Operational Research, v. 24, п. 4, 1973. EILON, S., COTERILL, D.J. A modified SI rule in job shop scheduling. International Journal of Production Research, v. 7, ก. 2,1968 tuações onde o número de moldes é igual a 42, o aumento no número de máquinas de 1 para 2 (um aumento de $100 \%$ ) resulta numa redução do percentual entregue com atraso de $26,25 \%$ para $14,45 \%$. Nos casos onde o número de moldes é 27, o mesmo aumento no número de máquinas resulta numa redução do percentual entregue com atraso de $21,83 \%$ para $18,87 \%$.

\section{CONCLUSÕES}

As conclusões dos resultados apresentados anteriormente podem ser divididas em dois níveis: o específico, relacionado diretamente com o sistema de produção estudado, e, o geral, relacionado com a questão de como analisar os impactos de decisōes e variáveis quando do projeto de um novo sistema de produção.

A nível específico, as conclusões mais interessantes têm a ver com a existência de interações de segunda ordem entre variáveis do sistema, além da comprovação de que o procedimento de partição de pedidos em lotes menores não contribui para a melhoria da performance do sistema, trazendo apenas um aumento da complexidade nos procedimentos de programação e controle da produção.

Em termos mais específicos, são as seguintes as principais conclusões:

1. de longe, o mais importante efeito principal sobre os prazos de entrega foi causado pela variação no nível nominal de utilização de capacidade. Este tipo de efeito já tinha sido observado em outros estudos realizados em sistemas de produção mais tradicionais; ${ }^{5}$

2. o aumento no valor médio do tempo de set up causa uma deterioração no desempenho de entrega do sistema. No entanto, embora este efeito tenha se mostrado estatisticamente significativo e independente de outras variáveis, sua magnitude é bastante pequena em relação aos demais efeitos;

3. existe uma grande interação entre o número de moldes e a relação núme- ro de estilos/número de máquinas, no que diz respeito às medidas de desempenho de entrega. Esta interação tem uma importância considerável devido à sua magnitude em relação aos outros efeitos. Em termos práti$\cos$, este resultado indica que o efeito sobre o desempenho de prazos de entrega, causado pelo aumento no número de moldes, depende fortemente da relação entre o número de estilos de produto e o número de máquinas;

\section{Em nivel mais geral, este} estudo traz algumas lições importantes. A primeira diz respeito à metodologia de análise e seu impacto sobre o processo de tomada de decisões quando do projeto $e$ dimensionamento de um novo sistema de produção.

4. uma comparaçáo entre as medidas de comportamento interno do sistema (tamanho da fila, ociosidade devido a set up) e as medidas de desempenho em prazo de entrega indica que em certas circunstâncias uma melhoria nas medidas internas corresponde a uma deterioração da performance externa (prazos de entrega).

Em nível mais geral, este estudo traz algumas lições importantes. A primeira diz respeito à metodologia de análise e seu impacto sobre o processo de tomada de decisões quando do projeto e dimensionamento de um novo sistema de produçẫo.

Do amplo conjunto de decisões que envolvem o projeto de um novo sistema de produção, existem aquelas relacionadas às regras de gerenciamento do sistema, como, por exemplo, a forma de programação da produção (particionar ou não encomendas em lotes menores para fabricação) ou o nível de utilização de 
capacidade (por exemplo, $65 \%$ ou $85 \%$ de ocupação média) e aquelas relacionadas com a aquisição de bens materiais, sejam ferramentas (compra de moldes) ou máquinas ( 1 ou 2 máquinas, por exemplo).

O que geralmente diferencia estas duas categorias de decisōes são o valor do investimento e a reversibilidade da decisão. A adoção de um novo procedimento para programação da produção ou de um maior número de horas de trabalho para controlar o nível de congestionamento do sistema podem ser feitas com quase nenhum investimento de capital e uma vez entendido que são de pouca utilidade podem ser rapidamente descontinuadas. Por outro lado, a aquisição de uma nova máquina, e principalmente de mais um molde, implica quase sempre um significativo investimento de capital, e uma vez adquiridos dificilmente se poderá modificá-los ou mesmo vendê-los. São, portanto, decisōes caras e de baixa reversibilidade, ou seja, seus impactos são duradouros e financeiramente significativos.

O uso de um modelo de simulação como o utilizado neste trabalho permite, portanto, examinar os impactos esperados de diferentes variáveis e decisões sobre o desempenho do sistema de produção, a um custo significativamente menor do que ocorreria caso se adotasse uma solução inadequada. Permite, o que é mais importante, a comparação de diversas alternativas, o que seria inviável no sistema real.

Além disso, a combinação de um modelo de simulação com uma boa estratégia de experimentos, no caso um projeto fatorial, onde as variáveis/decisões sejam os fatores e os valores/alternativas os níveis dos fatores, permite chegar a conclusōes bastante robustas sobre a relevância de variáveis e alternativas, através dos efeitos principais, além de per- mitir a identificação das interações entre variáveis, o que seria praticamente impossível em um sistema industrial real.

Uma outra observação importante, de cunho mais geral, diz respeito à importância das decisões de capacidade sobre o desempenho de sistemas de produção. É importante notar que existem diferentes formas de aumento de capacidade (maior número de moldes, maior índice de utilizaçăo da capacidade de máquina, melhor

E importante notar que existem diferentes formas de aumento de capacidade (maior número de moldes, maior índice de utilização da capacidade de máquina, melhor relação entre tipos de produtos $e$ número de máquinas), cada uma afetando de forma diferente o desempenho dos prazos de entrega, uma variável fundamental para a competitividade das organizações.

relação entre tipos de produtos e número de máquinas), cada uma afetando de forma diferente o desempenho dos prazos de entrega, uma variável fundamental para a competitividade das organizações.

Independentemente da melhor forma de aumentar a capacidade (no caso, através de uma menor taxa de utilização das horas de máquinas disponíveis) fica evidente a existência de um claro trade off entre investimento em capacidade e desempenho dos prazos de entrega. O uso de modelo de simulação permite em cada caso específico identificar a melhor alternativa e tomar a decisão mais adequada.

PALAVRAS CHAVE: Simulação, estrutura de produção, projeto de sistema de produção, sistema de produção.

KEY WORDS: Simulation, production structure, design of production systems, production system. 